\title{
Insustentabilidade do espaço geográfico em Quebrangulo-AL
}

Unsustainability of geographic space in Quebrangulo AL-

\author{
Felippe Pessoa de Melo
}

Mestre em Geociências e Análise de Bacias pela Universidade Federal de Sergipe-UFS - Governo do Estado de Alagoas

\begin{abstract}
Resumo
O município de Quebrangulo-AL é constantemente assolado por enchentes, as quais colocam em risco de vida a população local e causam grandes prejuízos geoambientais. Objetivando compreender esse fenômeno, utilizando as tecnologias do Sensoriamento Remoto e Sistema de Informações Geográficas (SIG), para confecção das cartas temáticas referentes à: hipsometria, geologia, drenagem, limites municipais... De posse desse material foi possível realizar uma análise geoambiental, da dinâmica de uso e ocupação do solo no município, a qual forneceu subsídios teóricos e metodológicos para implantação de políticas públicas governamentais sustentáveis.
\end{abstract}

Palavras Chave: Enchentes, sensoriamento remoto e geoambiental.

\begin{abstract}
The municipality of Quebrangulo-AL and constantly plagued by floods, which pose a risk to the local population lives and cause great damage geoenvironmental. In order to understand this phenomenon, using the technologies of Remote Sensing and Geographic Information System (GIS), for making the thematic maps relating to: hipsometria, geology, drainage, municipal boundaries... In possession of this material could make a geoenvironmental analysis, the dynamics of use and occupation of land in the city, which provided theoretical and methodological implementation of public policies for sustainable government.
\end{abstract}

Keywords: Floods, remote sensing and geoenvironmental. 


\section{INTRODUÇÃO}

O processo de urbanização em Quebrangulo -AL não levou em consideração as oscilações das vasões do rio Paraíba, de forma que a depender do regime de chuvas, o rio pode apresentar-se quase seco ou transbordar. E em ambos os casos causar grandes transtornos a população.

Em julho de 2010, 4.800 dos 12.000 habitantes do município foram atingidos diretamente pela cheia do rio Paraíba. Colocando a cidade em estado de calamidade pública, a população mais prejudicada foi a que ocupava as partes mais baixas da cidade, principalmente as que possuíam suas residências localizadas nas margens do rio. Só essa enchente foi responsável pela destruição de mais de 700 residências.

Dois anos após essa enchente o rio Paraíba começou a passar por um período de baixa vasão, sendo possível atravessa-lo andando de uma margem a outra. Nesse novo cenário, os prejuízos estão relacionados a perda das lavouras, falta de pasto para o gado... Aumentando de forma considerável o valor da cesta básica local e regional, pois Quebrangulo-AL abastece as cidades circunvizinhas com produtos como: feijão, milho, batata...

Existe uma intrínseca relação entre a população quebrangulana urbana e rural com o rio Paraíba. De forma que a economia local depende diretamente dos recursos hídricos provenientes do Paraíba.
Sendo que essa relação é conflituosa e insustentável, os esgotos do sítio urbano são despejados sem o devido tratamento no rio, sua mata ciliar foi removida para construção de residências no centro urbano e maximização da área voltada para atividades agrárias na zona rural.

Esse modelo de uso dos recursos hídricos está maximizando a contaminação desse corpo d'água, dinamizando o processo de assoreamento, diminuindo a fauna local e causando doenças de veiculação hídrica na população local e regional, logo os habitantes das cidades circunvizinhas consomem os produtos oriundos do campo de Quebrangulo-AL.

\section{Localização da área}

O município está localizado na porção centro-norte do estado de Alagoas, estando a 118 $\mathrm{km}$ de Maceió, capital alagoana.

As cidades polos mais próximas são: Palmeira dos Índios-AL, que fica a $24 \mathrm{~km}$ de distância, Viçosa-AL a $31 \mathrm{~km}$ e Arapiraca-AL a $63 \mathrm{~km}$. Essas três cidades prestam serviços principalmente relacionados aos setores primário e secundário.

Quebrangulo-AL faz divisa com sete cidades das quais três são pernambucanas e quatro são alagoanas, sendo elas: Bom Conselho-PE, Chã Preta-AL, Correntes-PE, Lagoa do Ouro-PE, Palmeira dos Índios-AL, Paulo Jacinto-AL e Viçosa-AL (Figura 01).

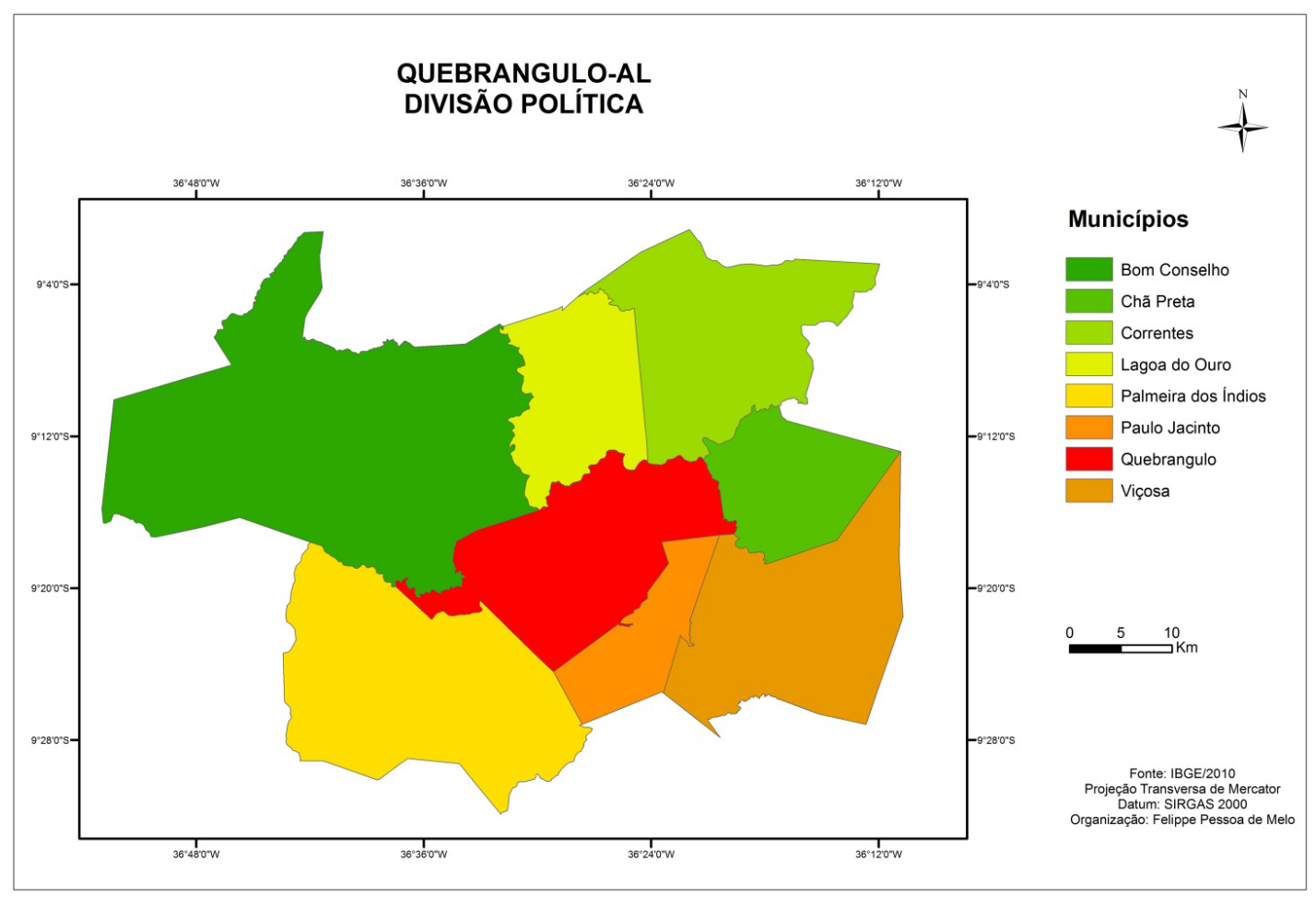




\section{METODOLOGIA}

Realizou-se uma pesquisa de gabinete, com a finalidade de conhecer o material bibliográfico referente à temática e baixar os dados vetoriais e matriciais correspondentes ao perímetro do local de estudo.

Logo em seguida confeccionou-se um banco de dados geográficos georreferenciados no SIG ArcGIS. De posse dos dados em um ambiente virtual foram feitas as correlações entre as informações, o que possibilitou a análise e interpretação dos fenômenos que estão ocorrendo na paisagem e confecção das cartas temáticas.

Posteriormente realizou-se a pesquisa de campo objetivando confirmar as informações obtidas em gabinete, editar e reambular quando necessário. Após essa etapa as cartas temáticas foram reinterpretadas e reanalisadas, proporcionando dados fidedignos à realidade.

\section{RESULTADOS E DISCUSSÕES}

Quebrangulo-AL apresenta cotas altimétricas que oscilam de 240 a 930m (Figura 02), aplicando o modelo de classificação toxonômica do relevo proposto por Ross (1992), foram encontradas nove Unidades Morfológicas ou Padrões de Formas (Tabela 01).

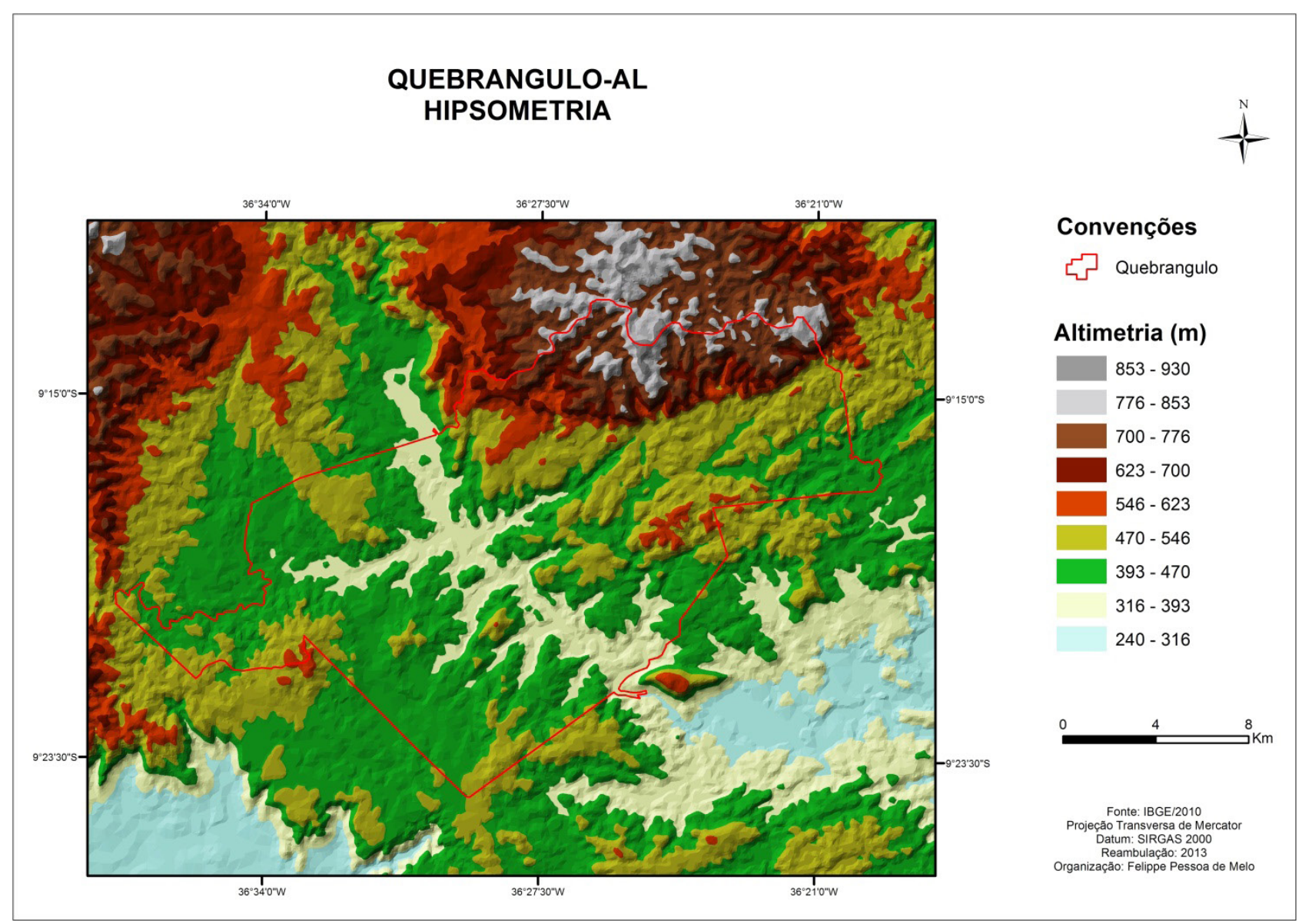

Tabela 01. Subdivisões do modelado.

\begin{tabular}{c|c|c|c|c|c}
\hline Altimetria $(\mathrm{m})$ & Área $\left(\mathrm{Km}^{2}\right)$ & Percentual $(\%)$ & Altimetria $(\mathrm{m})$ & Área $\left(\mathrm{Km}^{2}\right)$ & Percentual $(\%)$ \\
\hline $853 / 970$ & 6.54 & 0.20 & $470 / 546$ & 896.88 & 28.01 \\
\hline $776 / 853$ & 91.20 & 2.84 & $393 / 470$ & 1.489 .37 & 46.51 \\
\hline $700 / 776$ & 206.33 & 6.44 & $316 / 393$ & 411.39 & 12.84 \\
\hline $623 / 700$ & 806.96 & 25.20 & $240 / 316$ & 0.11 & 0.003 \\
\hline $546 / 623$ & 100.10 & 3.12 & --------------------------------- \\
\hline \multicolumn{5}{c}{ Área Total $\left(\mathrm{Km}^{2}\right)$} & \multicolumn{5}{|c|}{3.201 .92} \\
\hline
\end{tabular}


Tabela 02. Recursos minerais.

\begin{tabular}{c|l}
\hline Unidades Geológicas & \multicolumn{1}{c}{ Minerais } \\
\hline Belém do São Francisco & $\begin{array}{l}\text { Ortognaisse tonalítico, granítico, migmatito, ortognaisse } \\
\text { granodiorítico e metadiorito. }\end{array}$ \\
\hline Cabrobó (01) & $\begin{array}{l}\text { Metamáfica, metagrauvaca, quartzito, formação ferrífera } \\
\text { bandada, biotita xisto, rocha calcissilicática, biotita } \\
\text { gnaisse, mármore, muscovita-biotita xisto, muscovita- } \\
\text { biotita gnaisse, rocha metaultramáfica, paramigmatito... }\end{array}$ \\
\hline Cabrobó (01)/ Migmatitos & Paramigmatito e paragnaisse. \\
\hline Ganitóides Indiscriminados & $\begin{array}{l}\text { Metatonalito, ortognaisse, metagranito, metagranodiorito, } \\
\text { metamonzodiorito... }\end{array}$ \\
\hline Ouro Branco & Garanodiorito e monzonito. \\
\hline Plúton & $\begin{array}{l}\text { Quartzo álcali-feldspato sienito, quartzo monzonito, } \\
\text { quartzo sienito. }\end{array}$ \\
\hline Águas Belas & Quartzo sienito, granito e monzogranito. \\
\hline
\end{tabular}

Geologicamente está inserido em sete formações distintas (Tabela 02) e apresenta uma falha transcorrente sinitral de $15.82 \mathrm{Km}$, a qual parte da porção central do município em direção a noroeste (Figura03).

Dentro dos limites municipais encontram-se os solos: Latossolos amarelos distróficos e Neossolos litólicos eutróficos (Figura 04). O primeiro possui uma área de $1.439 .96 \mathrm{Km}^{2}$, equivalendo a $44.97 \%$ do território municipal e o segundo tem um perímetro de $1.761 .96 \mathrm{Km}^{2}$, o que corresponde a $55.03 \%$ do município. Sua cobertura vegetal original era formada principalmente pela caatinga hipoxerófila (Figura 05), com uma área de $3.155 .9 \mathrm{Km}^{2}$ o que equivale a $98.57 \%$ do perímetro municipal. Existindo uma pequena presença de uma flora subcaducifólia e subperenifólia na porção nordeste do seu território, essas duas coberturas ocupavam uma área de $46.02 \mathrm{~km}^{2}$, ou seja, $1.43 \%$ do município.

Atualmente só existem resquícios dessas vegetações, devido a ações como: a retirada da

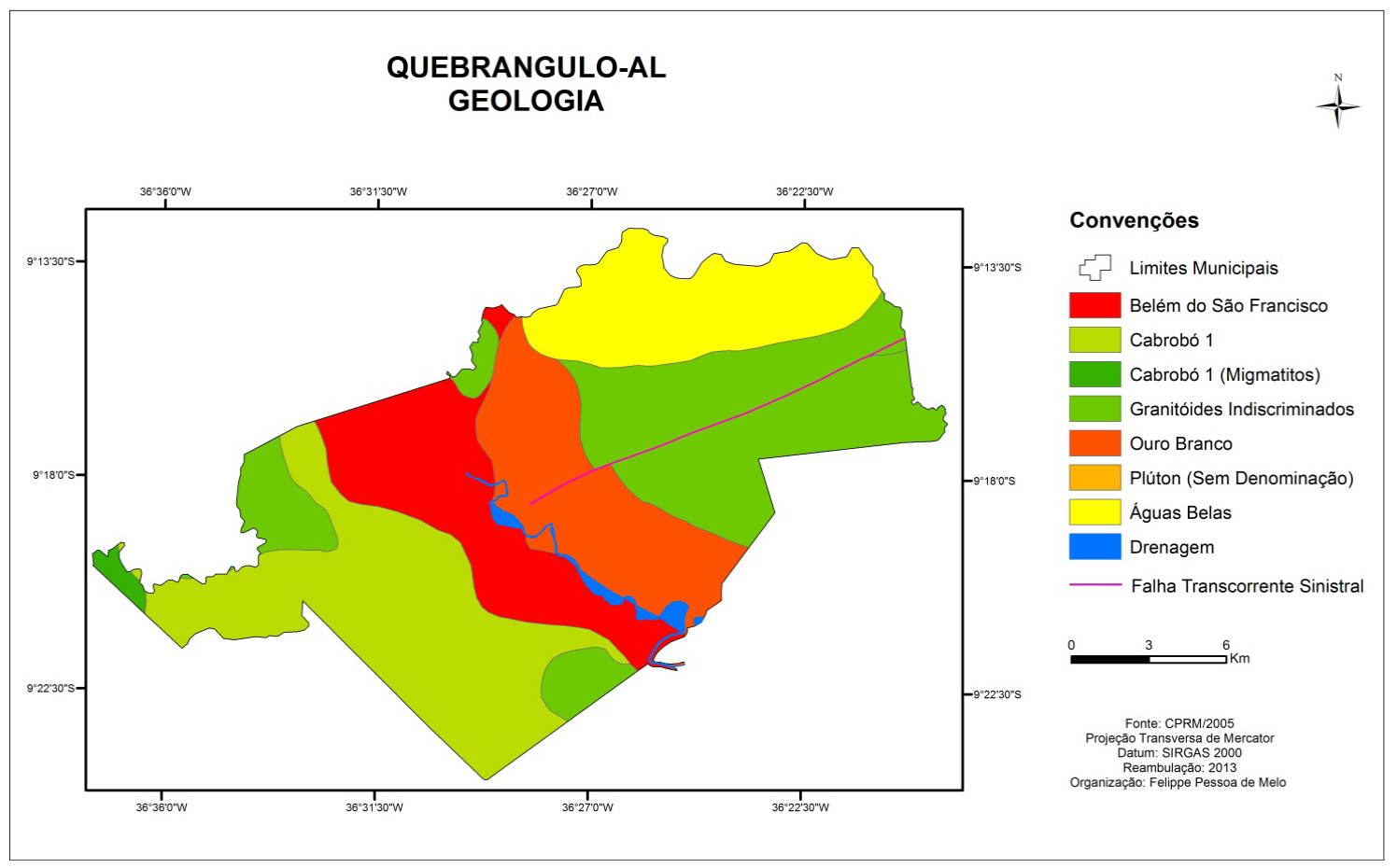

Figura 03. Unidades geológicas. 


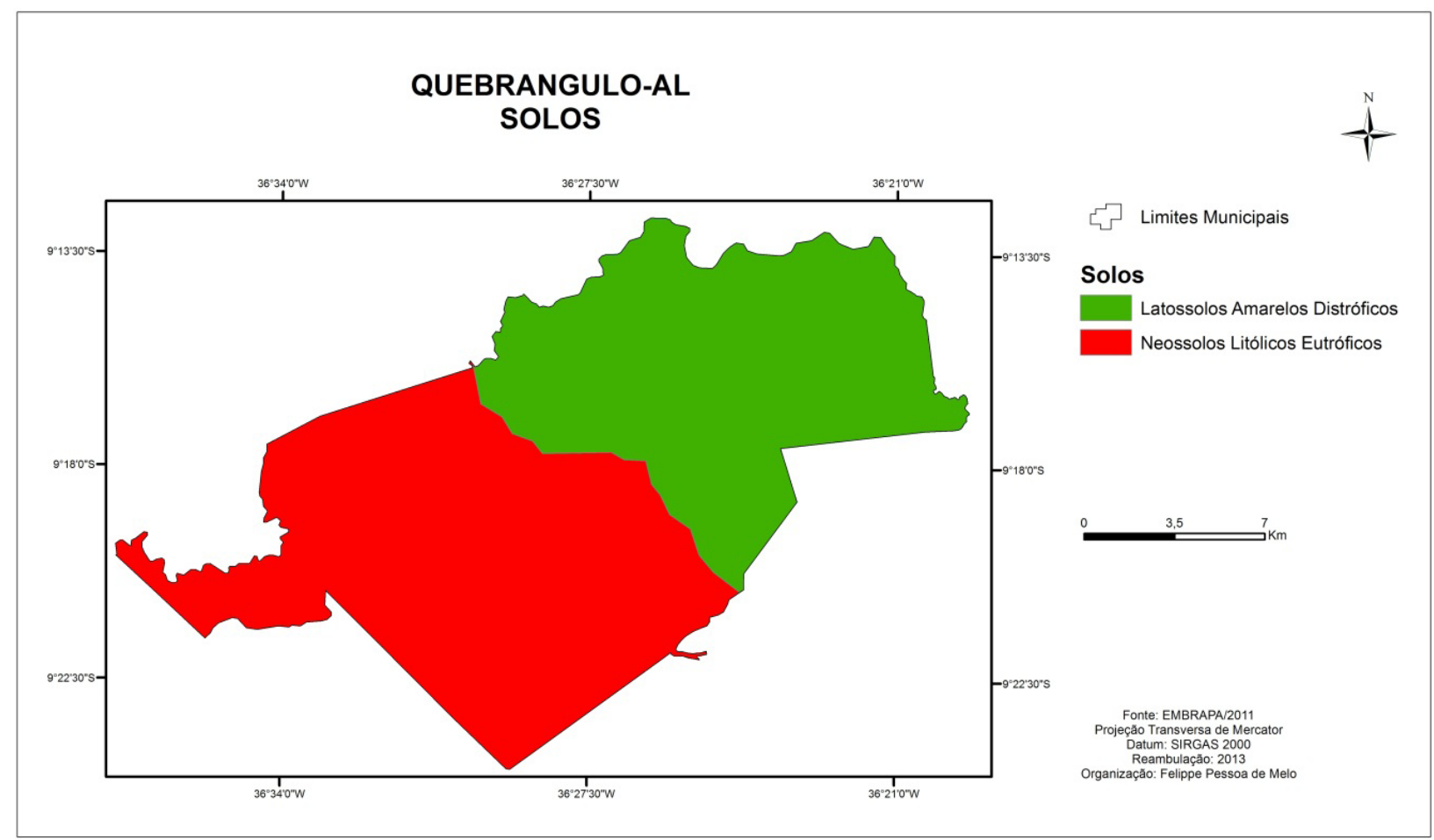

Figura 04. Tipos de solos.

vegetação original para maximização das atividades agrárias, ampliação do sítio urbano, fornecimento de madeira para os fornos das padarias e para os festejos juninos, confecção de estacas para demarcação das propriedades agrícolas...

A remoção da flora ocorreu de forma insustentável, ocasionando diversos problemas geoambientais, dentre eles destacam-se: redução da fauna, intensificação dos processos erosivos, assoreamento do rio Paraíba, minimização do potencial turístico, formação de ilhas de calor, invasão de insetos e aracnídeos nas residências,

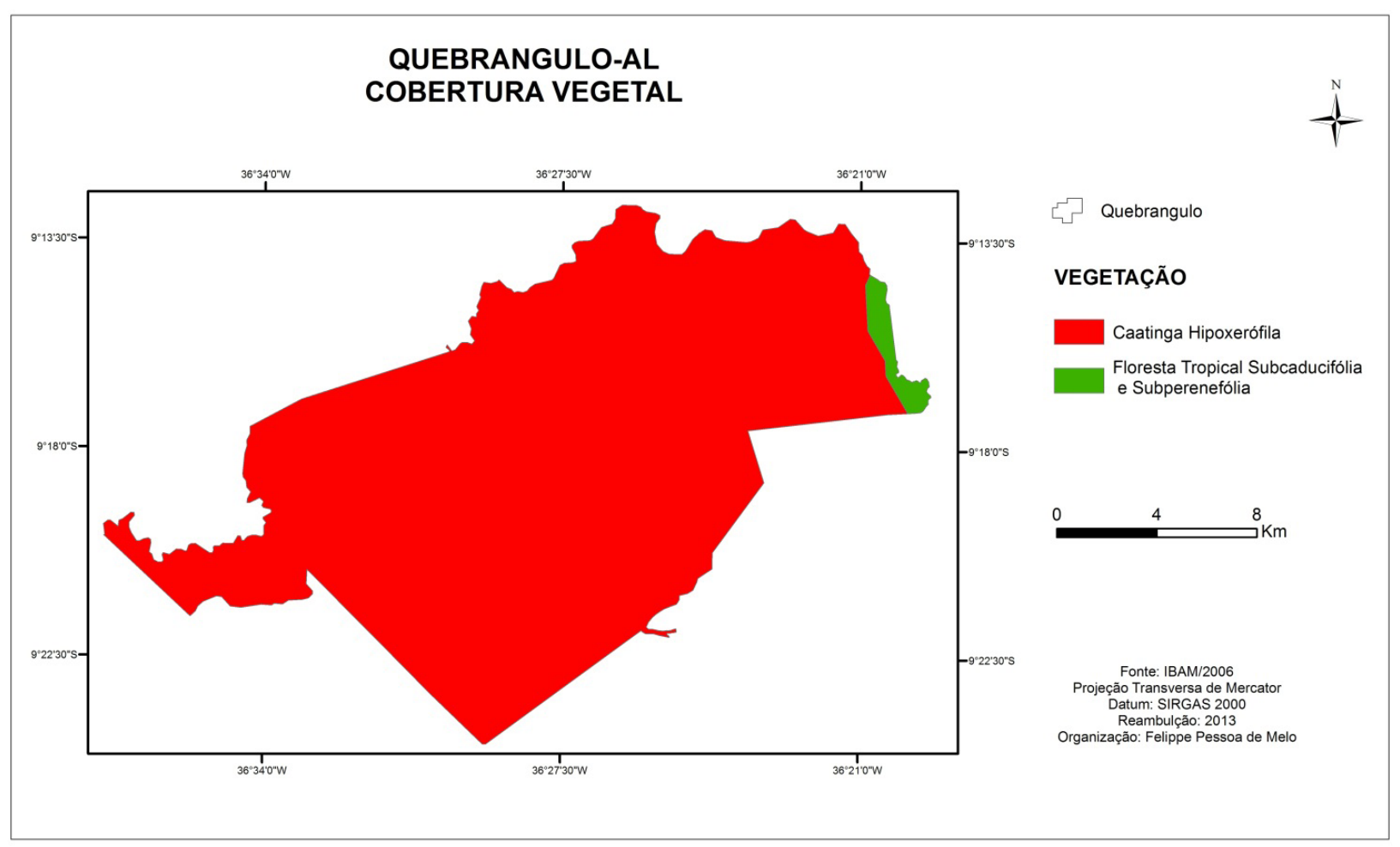

Figura 05. Cobertura vegetal. 


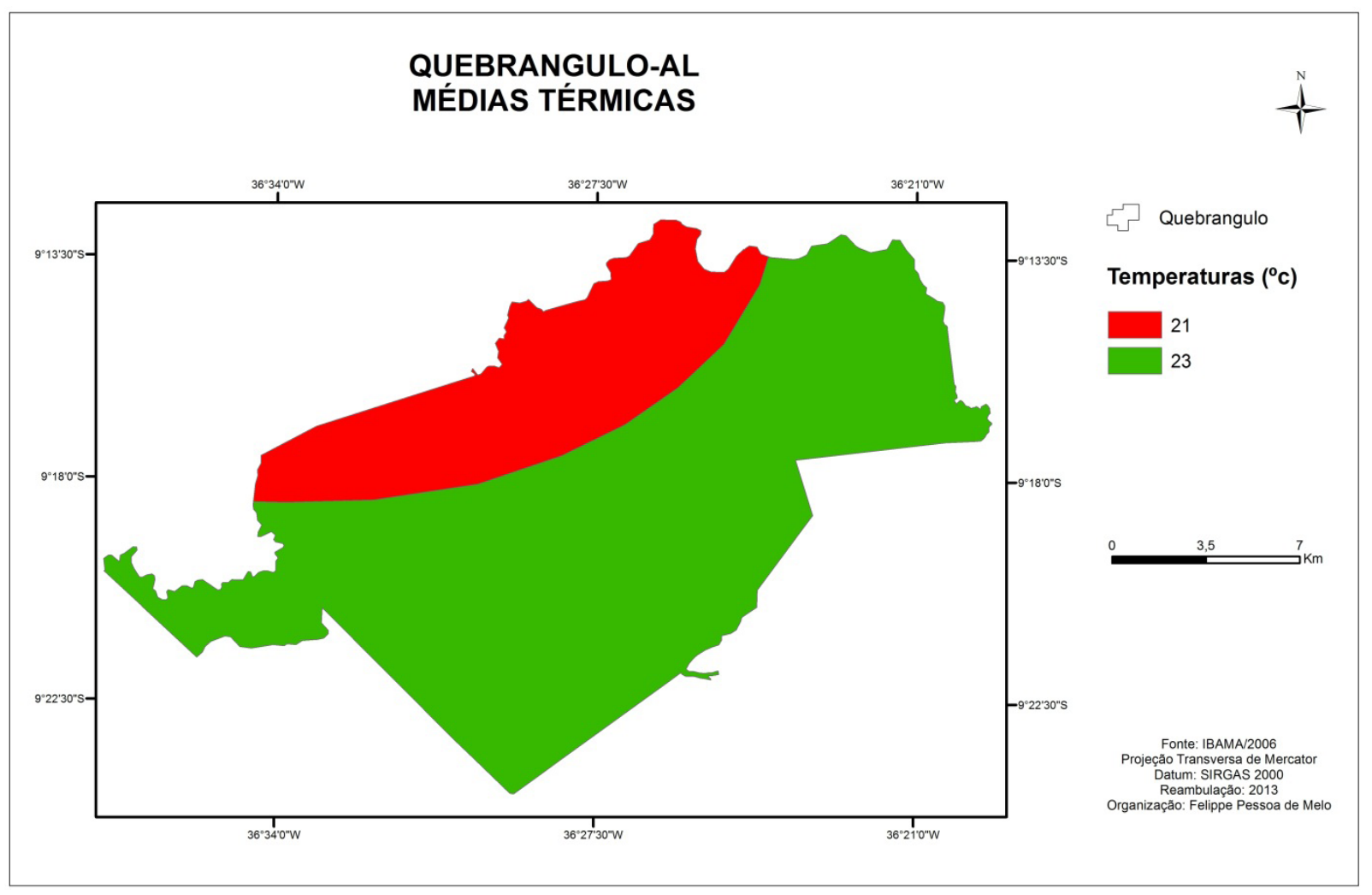

Figura 06. Sistema Térmico.

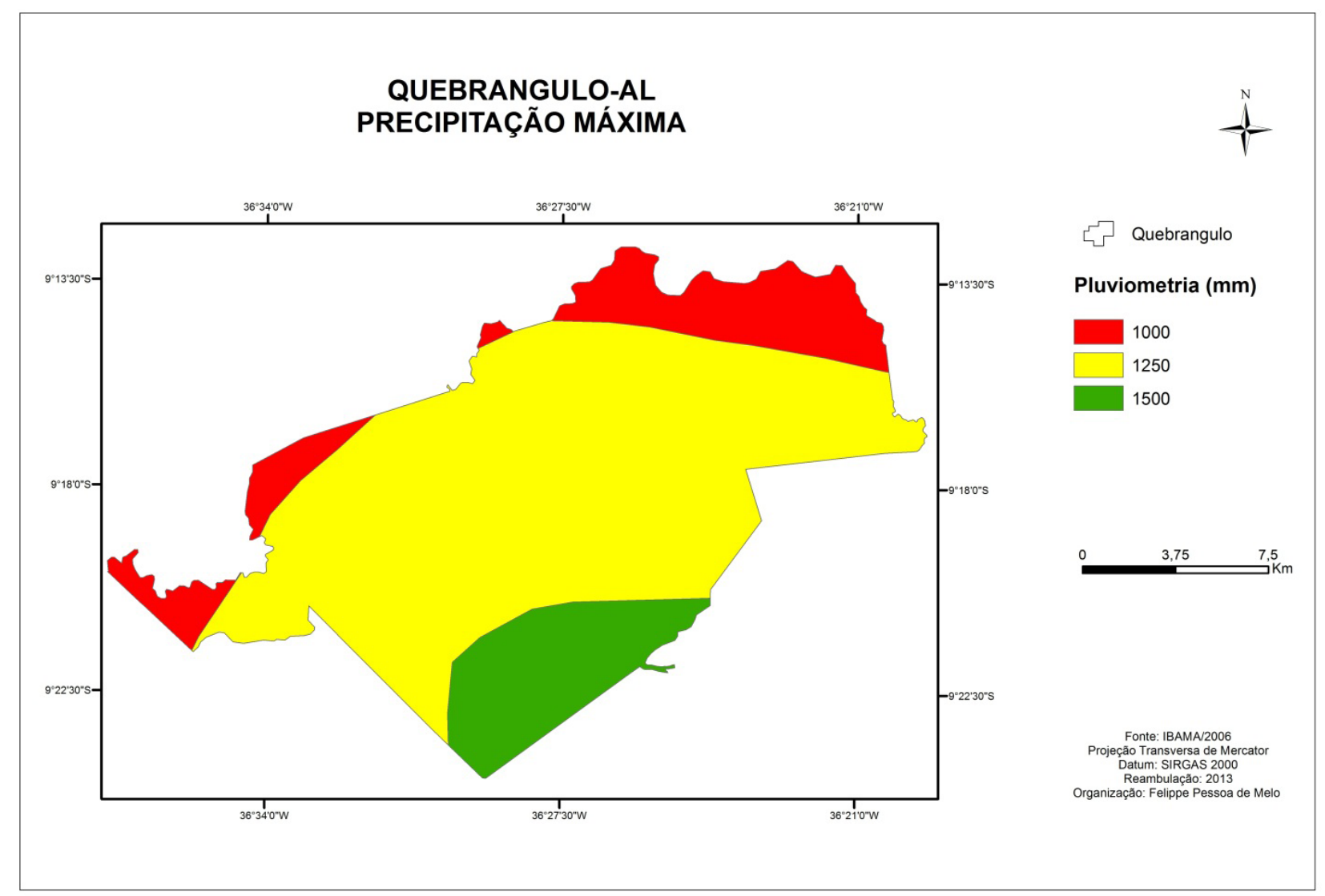

Figura 07. Precipitação. 


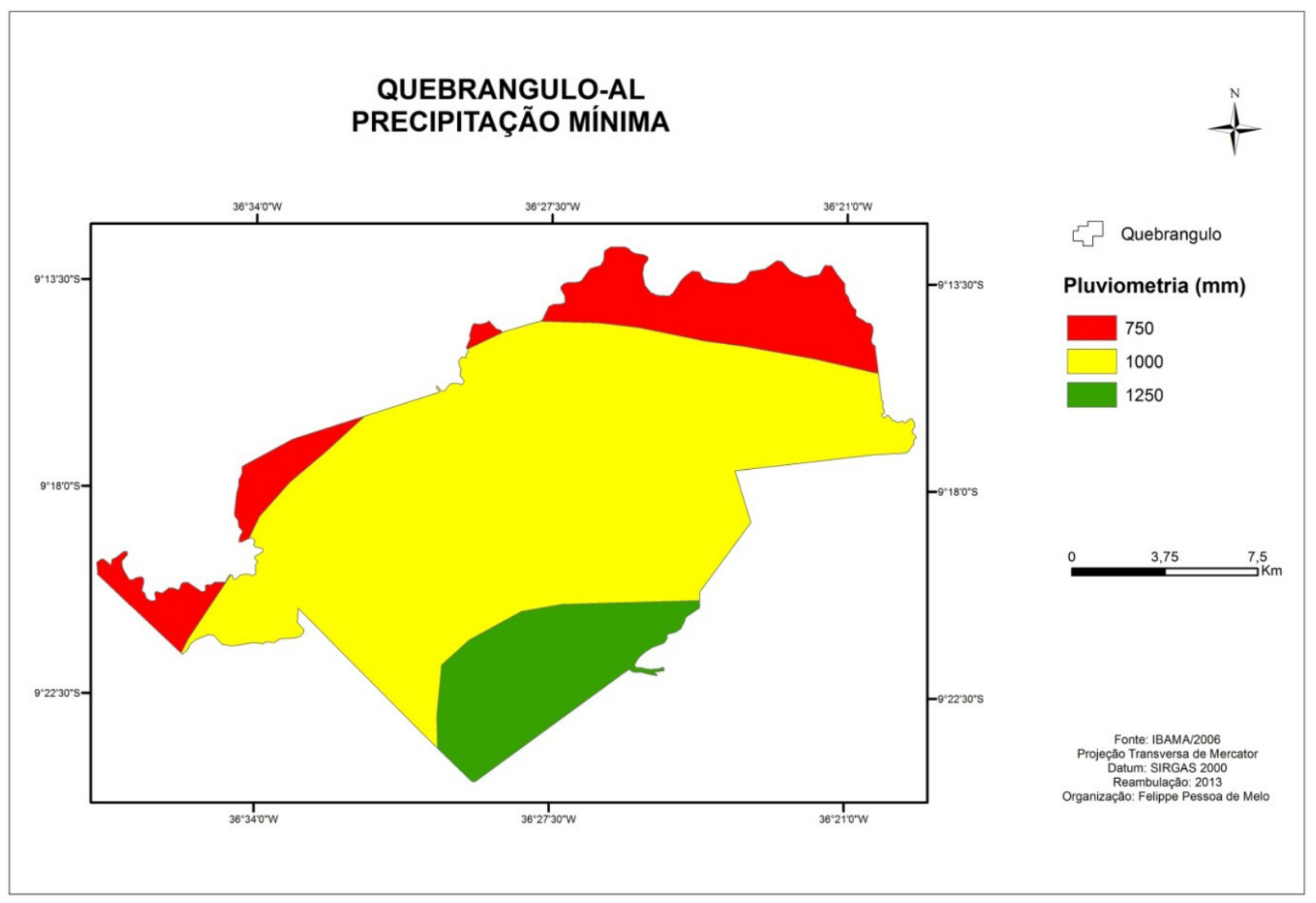

Figura 08. Precipitação.

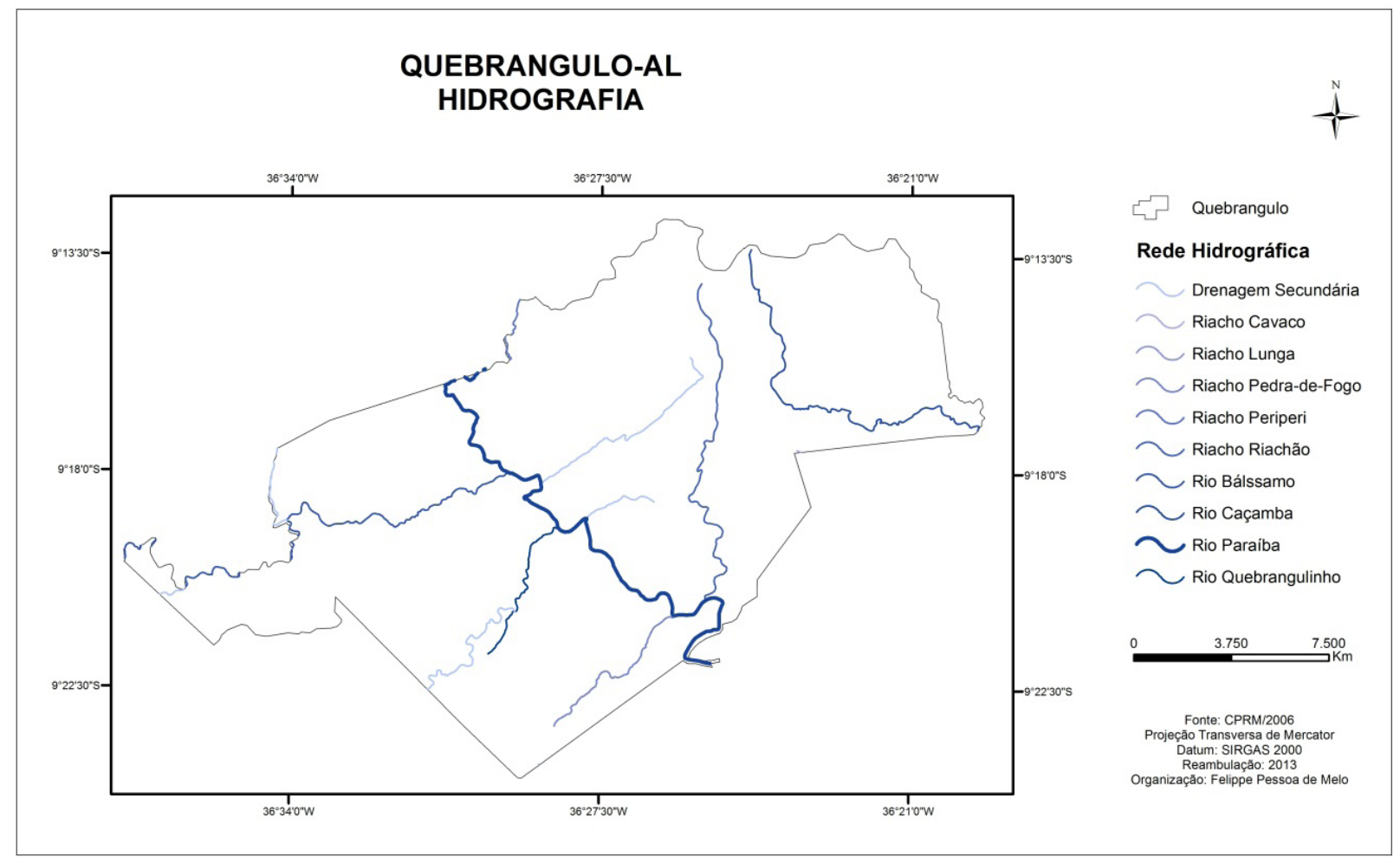

Figura 09. Drenagem. 
perda de solos...

O clima predominante no município é o semiárido, as temperaturas médias são de $21^{\circ} \mathrm{C}$ nas áreas localizadas entre o extremo norte nordeste e o noroeste (Figura 06), totalizando $801.36 \mathrm{Km}^{2}$, ou seja, 25.02\% de Quebrangulo-AL. Nas demais porções do território a media térmica é de $23^{\circ} \mathrm{C}$.

Suas precipitações podem atingir 1500 mm nos períodos mais chuvosos (Figura 07), que vão de maio a agosto e $750 \mathrm{~mm}$ nas épocas mais secas (Figura 08), de setembro a abril. Podendo ocorrer eventuais variações nesse sistema climático. Principalmente devido a forte interferência antrópica na paisagem.

O principal rio da sua rede hidrológica é o Paraíba (Figura 09), o qual está com sua mata ciliar desmatada.

De acordo com novo código florestal brasileiro o rio Paraíba deveria ter uma área de preservação permanente de $50 \mathrm{~m}$ nas extensões de suas margens, nos demais corpos d'água a APP deveria ser de $30 \mathrm{~m}$ nas bordas de ambas as margens.

Dessa forma Quebrangulo-AL apresenta um déficit de áreas verdes de preservação permanente referentes a cursos d'agua de $80.02 \mathrm{Km}^{2}$, o que representa $2.49 \%$ do território do município.

\section{CONCLUSÕES}

O município de Quebrangulo-AL possui peculiaridades topográficas e pluviométricas que não foram levadas em consideração pelos processos de implantação do sítio urbano e de estruturação do setor primário.

De forma que não são necessários grandes volumes pluviométricos para que as águas do rio Paraíba tenham suas forças maximizadas e com isso provoquem transtornos nas zonas rural e urbana. Logo do ponto mais alto do município para o mais baixo existe uma diferença altimétrica de $594 \mathrm{~m}$.

Para agravar ainda mais a situação os sistemas de drenagens que estão dentro dos limites municipais não possuem mata ciliar, ela foi removida no sítio urbano para construção de moradias, e nas áreas rurais a essa cobertura vegetal foi retirada para maximizar as áreas agrárias. Os locais onde ainda apresentam nascentes de águas, as quais servem de repositório para os cursos de águas no município, não apresentam a faixa mínima de $50 \mathrm{~m}$ ao seu redor. Práticas como as queimadas para limpar as terras para a agricultura também são bem comuns.

Portanto para reverter esse cenário de degra- dação geoambiental é necessário à implantação de um plano diretor municipal que contemple os princípios da sustentabilidade. Evitando assim tragédias anunciadas, como as que ocorreram em 2010 e planos de reconstrução municipal que reconstroem as residências nos mesmos locais. De forma que no próximo período chuvoso o transtorno se repete. O que além de colocar a população em risco de vida, gera ônus para os cofres públicos.

\section{REFERÊNCIAS BIBLIOGRÁFICAS}

CPRM-Companhia de Pesquisa de Recursos Minerais. Geobank. Disponível em: < http://geobank. sa.cprm.gov.br/>. Acesso em 22 de mar. 2013.

EMBRAPA-Empresa Brasileira de Pesquisa Agropecuária. Brasil em Relevo. Disponível em: $<\underline{\text { http: } / /}$ www.relevobr.cnpm.embrapa.br/index.htm>. Acesso em 10 de jan. 2012.

IBAMA- Instituto Brasileiro do Meio Ambiente e dos Recursos Naturais Renováveis. Temas Vetoriais Formato Shapefile. Disponível em: <http://siscom. ibama.gov.br/shapes>. Acesso em 22 de jan. 2013.

IBGE-Instituto Brasileiro de Geografia e Estatística. Banco de Dados. Disponível em: < http://www.ibge. gov.br/home/default.php $>$. Acesso em 20 de mar. 2012.

INMET-Instituto Nacional de Meteorologia. Estações e Dados. Disponível em: < http://www.inmet. gov.br/portal>. Acesso em 22 de mai. 2012.

INPE-Instituído Nacional de Pesquisas Espaciais. Catálogo de Imagens. Disponível em: <http://www. dgi.inpe.br/CDSR/>. Acesso em 18 de mar. 2012.

Portal Brasil. Código Florestal. Disponível em: $<$ http://www.brasil.gov.br/sobre/meio-ambiente/ legislacao-e-orgaos/codigo-florestal> . Acesso em: 26 de mar. 2013.

ROSS, J. L. S. 1992. O Registro Cartográfico dos Fatos Geomórficos e a Questão da Taxonomia do Relevo. São Paulo. Revista do Departamento de Geografia. 6: 17-29. 